\section{THU0401 IMPACT OF BODY COMPOSITION MEASURES ON THE RESPONSE TO BIOLOGICAL DISEASE-MODIFYING ANTI-RHEUMATIC DRUGS IN PATIENTS WITH ANKYLOSING SPONDYLITIS}

V. Rios Rodriguez ${ }^{1,2}$, M. Protopopov ${ }^{1}$, F. Proft ${ }^{1}$, J. Rademacher ${ }^{1,2}$, B. Muche ${ }^{1}$, A. K. Weber ${ }^{1}$, S. Lüders ${ }^{1}$, H. Haibel ${ }^{1}$, M. Verba ${ }^{1}$, J. Sieper', D. Poddubnyy ${ }^{1,3}$. ${ }^{1}$ Charité - Universitätsmedizin Berlin, Berlin, Germany; ${ }^{2}$ Berlin Institute of Health, Berlin, Germany; ${ }^{3}$ Deutsches Rheuma-Forschungszentrum (DRFZ), Berlin, Germany

Background: Data on the impact of body weight and body mass index (BMI) on the response to biological disease-modifying anti-rheumatic drugs (bDMARDs) in axial spondyloarthritis (axSpA) including ankylosing spondylitis (AS) are still contradictory. Data on the impact of different components of the body composition on the treatment response are lacking.

Objectives: To investigate the impact of body composition on the response to biological disease-modifying anti-rheumatic drugs (bDMARD) in patients with AS after 6 months of treatment.

Methods: Patients with AS (radiographic axSpA), fulfilling the modified New York criteria and starting a bDMARD therapy were recruited between 2015 and 2019 in an extension of the prospective German Spondyloarthritis Inception Cohort (GESPIC-AS). All patients were required to be candidates for bDMARD therapy at baseline with high disease activity (BASDAI $>=4$ and/or ASDAS > $>2.1$ ) despite previous treatment with nonsteroidal anti-inflammatory drugs. Disease activity measures (BASDAI, CRP, ASDAS), as well as body composition parameters were assessed at baseline and after 6 months of bDMARD treatment. Body composition was assessed by the bioelectrical impedance analysis (BIA). Weight, body mass index (BMI), fat mass index (FMI), fat free mass index (FFMI), skeletal muscle mass value (SMM), visceral adipose tissue (VAT), total body water (TBW), and extracellular water (ECW) values were collected. The primary measure of the treatment response was ASDAS change at month 6 as compared to baseline. Results: A total of 129 patients with AS were included in this cohort. BIA was performed in 77 patients. There were $71.4 \%$ males, and $85.7 \%$ were HLA-B27 positive. At baseline, BASDAl was $5.4 \pm 1.4$, CRP was $12.8 \pm 16.5 \mathrm{mg} / \mathrm{l}$, and ASDAS - 3.0 1 1.0. The baseline BMI was $25.0 \pm 4.3 \mathrm{~kg} / \mathrm{m}^{2}$. A total of 75 patients were treated with $\mathrm{TNFi}, 2$ patients received an IL-17 inhibitor.

A higher BMI at baseline was associated with a worse response to bDMARD therapy that was attributable to both, the fat mass as reflected by FMI and to the fat-free mass reflected by FFMI, but not to SMM or VAT or water components Table. This effect was independent of age, sex, symptom duration, HLA-B27 status and ASDAS at baseline.

Conclusion: Both fat mass and fat free mass have an impact on the response to bDMARDs after 6 months of treatment in patients with AS. Interestingly, skeletal muscle mass, visceral fat as well as water components showed no association with treatment response.

Acknowledgments: GESPIC has been financially supported by ArthroMark and METARTHROS projects.

Disclosure of Interests: : Valeria Rios Rodriguez Consultant of: Abbvie, Novartis, Mikhail Protopopov Consultant of: Novartis, Fabian Proft Grant/research support from: Novartis Pharma GmbH, Consultant of: Consultancy / speaker fees from: Abbvie, BMS, Celgene, Lilly, MSD, Novartis, Pfizer, Roche, UCB, Speakers bureau: Consultancy / speaker fees from: Abbvie, BMS, Celgene, Lilly, MSD, Novartis, Pfizer, Roche, UCB, Judith Rademacher: None declared, Burkhard Muche: None declared, Anne Katrin Weber: None declared, Susanne Lüders:
None declared, Hildrun Haibel Consultant of: Abbvie, Jansen, MSD, and Novartis, Speakers bureau: Abbvie, Jansen, MSD, and Novartis, Maryna Verba: None declared, Joachim Sieper Consultant of: AbbVie, Boehringer Ingelheim, Eli Lilly and Company, Janssen, Merck, Novartis, Pfizer, Roche, and UCB Pharma, Speakers bureau: AbbVie, Boehringer Ingelheim, Eli Lilly and Company, Janssen, Merck, Novartis, Pfizer, Roche, and UCB Pharma, Denis Poddubnyy Grant/ research support from: AbbVie, MSD, Novartis, and Pfizer, Consultant of: AbbVie, Bristol-Myers Squibb, Eli Lilly, MSD, Novartis, Pfizer, Roche, UCB, Speakers bureau: AbbVie, Bristol-Myers Squibb, Eli Lilly, MSD, Novartis, Pfizer, Roche, UCB

DOI: 10.1136/annrheumdis-2020-eular.6197

\section{THU0402 SERUM MARKERS OF BONE RESORPTION, FORMATION, AND MINERALIZATION DURING 8 YEARS OF TNF-A BLOCKING THERAPY IN PATIENTS WITH ANKYLOSING SPONDYLITIS}

M. Siderius ${ }^{1}$, A. Spoorenberg ${ }^{1}$, S. Arends ${ }^{1} .^{1}$ University Medical Center Groningen, Rheumatology and Clinical Immunology, Groningen, Netherlands

Background: Ankylosing spondylitis (AS) is a chronic inflammatory disease, characterized by both excessive bone formation and bone loss. The bone turnover marker (BTM) bone-specific alkaline phosphatase (BALP) plays a central role in bone mineralization. Our previous study demonstrated that 3 years of TNFa blocking therapy results in a significant increase in BALP. ${ }^{1}$ However, longer follow-up is needed to investigate whether BALP stays elevated during TNF-a blocking therapy and also to explore the course of other BTM, osteocalcin (OC), procollagen type $1 \mathrm{~N}$-terminal peptide (PINP) and serum type 1 collagen $\mathrm{C}$-telopeptide (SCTX) in AS.

Objectives: To evaluate serum markers of bone resorption, formation, and mineralization during 8 years of TNF-a blocking therapy in AS patients.

Methods: Included were consecutive AS outpatients from the University Medical Center Groningen (UMCG) attending the Groningen-Leeuwarden Axial SpA (GLAS) cohort and who were treated with a maximum of 2 TNF-a blockers for at least 8 years. Patients were excluded when they used bisphosphonates at baseline or during follow-up. Data for a specific visit was coded as missing when patients either had experienced a fracture or received systemic corticosteroids within 1 year of that particular visit. Clinical and laboratory measurements were performed at baseline (before start of TNF-a blocking therapy), 3 and 6 months as well as 1, 2, 4, 6 and 8 years. Markers of bone formation OC, PINP and BALP, and marker of bone resorption SCTX were measured in serum. Z-scores of BTM were calculated using matched 10-years-cohorts of a Dutch reference group to correct for the normal influence that age and gender have on bone turnover Serum levels of 25 -hydroxyvitamin D $(25(\mathrm{OH}) \mathrm{D} 3)$ were assessed yearly. Generalized estimating equations were used to analyze BTM Z-scores over time within patients. Simple contrast was used to compare follow-up visits to baseline. P-values $<0.05$ were considered statistically significant.

Results: In total, 37 AS patients were analyzed; $62 \%$ were male, $86 \% \mathrm{HLA}$ B27+, mean age was $38.6 \pm 10.4$ years, median symptom duration 14 years (IQR 10-25), median CRP $13 \mathrm{mg} / \mathrm{L}$ (IQR 6-25), and $30 \%$ had low vitamin 25(OH)D3 status $(<50)$ at baseline. $35 \%$ of patients switched to a second TNF-a inhibitor during follow-up. ASDAS $3.8 \pm 0.9$ at baseline to $1.9 \pm 0.9$ after 8 years of follow-up $(P<0.001) .25(\mathrm{OH}) \mathrm{D} 3$ levels were stable at group level, median $58 \mathrm{nmol} / \mathrm{L}$ (IQR 45-70) at baseline and $60 \mathrm{nmol} / \mathrm{L}$ (IQR 50-70) after 8 years. Bone regulation marker OC Z-score was

Table. Univariable and multivariable linear regression analysis of the association between response to bDMARD treatment (change in the ASDAS score after 6 months) and body composition parameters in patients with AS ( $n=77)$

\begin{tabular}{|c|c|c|c|c|c|c|c|c|}
\hline Variables & Univariable & Multivariable analysis* & & & & & & \\
\hline & $\begin{array}{l}\text { Analysis } \\
\text { B (95\%Cl) }\end{array}$ & $\begin{array}{c}\text { Model } 1 \\
\text { B }(95 \% \mathrm{Cl})\end{array}$ & $\begin{array}{c}\text { Model } 2 \\
\text { B }(95 \% \mathrm{Cl})\end{array}$ & $\begin{array}{c}\text { Model } 3 \\
\text { B }(95 \% \mathrm{Cl})\end{array}$ & $\begin{array}{c}\text { Model } 4 \\
\text { B }(95 \% \mathrm{Cl})\end{array}$ & $\begin{array}{c}\text { Model } 5 \\
\text { B }(95 \% \mathrm{Cl})\end{array}$ & $\begin{array}{c}\text { Model } 6 \\
\text { B }(95 \% \mathrm{Cl})\end{array}$ & $\begin{array}{c}\text { Model } 7 \\
\text { B }(95 \% \mathrm{Cl})\end{array}$ \\
\hline$\overline{B M I}, \mathrm{~kg} / \mathrm{m} 2$ & $\begin{array}{c}-0.016 \\
(-0.063 ; 0.031)\end{array}$ & $\begin{array}{c}-0.043 \\
(-0.079 ;-0.006)\end{array}$ & - & - & - & - & - & - \\
\hline $\mathrm{FMl}, \mathrm{kg} / \mathrm{m} 2$ & $\begin{array}{c}-0.024 \\
(-0.103 ; 0.054)\end{array}$ & - & $\begin{array}{c}-0.065 \\
(-0.128 ;-0.003)\end{array}$ & - & - & - & - & - \\
\hline $\mathrm{FMMI}, \mathrm{kg} / \mathrm{m} 2$ & $\begin{array}{c}-0.010 \\
(-0.133 ; 0.112)\end{array}$ & - & - & $\begin{array}{c}-0.138 \\
(-0.253 ;-0.022)\end{array}$ & - & - & - & - \\
\hline SMM, kg & $\begin{array}{c}0.026 \\
(-0.020 ;-0.071)\end{array}$ & - & - & - & $\begin{array}{c}0.012 \\
(-0.044 ; 0.069)\end{array}$ & - & - & - \\
\hline VAT, liters & $\begin{array}{c}0.069 \\
(-0.099 ; 0.238)\end{array}$ & - & - & - & - & $\begin{array}{c}-0.095 \\
(-0.248 ; 0.057)\end{array}$ & - & - \\
\hline TBW, liters & $\begin{array}{c}0.020 \\
(-0.016 ; 0.056)\end{array}$ & - & - & - & - & - & $\begin{array}{c}0.007 \\
(-0.036 ; 0.051)\end{array}$ & - \\
\hline ECW, liters & $\begin{array}{c}0.054 \\
(-0.43 ; 0.150)\end{array}$ & - & - & - & - & - & - & $\begin{array}{c}0.005 \\
(-0.98 ; 0.107)\end{array}$ \\
\hline
\end{tabular}

${ }^{*}$ Adjusted for age, sex, HLA-B27 status, symptom duration, and ASDAS at baseline.

BMI: Body Mass Index; FMI: Fat Mass Index; SMM: Skeletal Muscle mass; VAT: Visceral Adipose Tissue; AS: ankylosing spondylitis; bDMARD: biological disease-modifying anti-rheumatic drug $\mathrm{Cl}: 95 \%$ confidence interval. 